\title{
Determinants of long-term outcome in patients after percutaneous stent-assisted management of symptomatic subclavian or innominate artery stenosis or occlusion
}

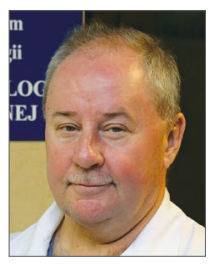

Tadeusz Przewlocki $^{1 *}$, MD, PhD; Leszek Wrotniak ${ }^{1}, \mathrm{MD}$; Anna Kablak-Ziembicka ${ }^{1}, \mathrm{MD}, \mathrm{PhD}$; Piotr Pieniazek ${ }^{1}, \mathrm{MD}, \mathrm{PhD}$; Agnieszka Roslawiecka ${ }^{1}, \mathrm{MD}$; Daniel Rzeznik ${ }^{1}, \mathrm{MD}, \mathrm{PhD}$; Marcin Misztal'2, MD, PhD; Wojciech Zajdel ${ }^{1}, \mathrm{MD}, \mathrm{PhD}$; Rafał Badacz' ${ }^{1}$ MD; Andrzej Sokolowski ${ }^{3}, \mathrm{PhD}$; Mariusz Trystula², MD, PhD; Piotr Musialek ${ }^{4}, \mathrm{MD}$, DPhil; Krzysztof Zmudka', MD, PhD

1. Department of Interventional Cardiology, Institute of Cardiology, Jagiellonian University School of Medicine, The John Paul II Hospital, Krakow, Poland; 2. Department of Vascular and Endovascular Surgery, Jagiellonian University School of Medicine, The John Paul II Hospital, Krakow, Poland; 3. Department of Statistics, University of Economics, Krakow, Poland; 4. Department of Cardiac and Vascular Diseases, Institute of Cardiology, Jagiellonian University School of Medicine, The John Paul II Hospital, Krakow, Poland

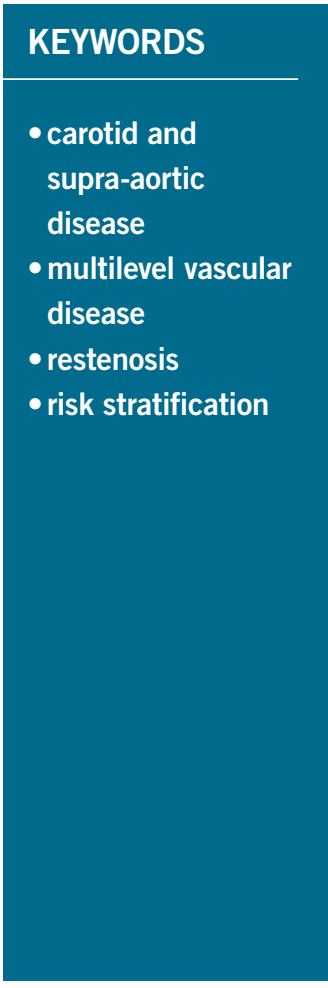

\begin{abstract}
Aims: Incidence and determinants of restenosis and adverse events after endovascular management $(\mathrm{PTA} \pm$ stent $)$ of the subclavian/innominate artery (SA/IA) stenosis/occlusion remain unclear due to the relatively short-term follow-up or limited size of prior studies. This large-scale, long-term prospective study investigated safety, efficacy, and prognosis after SA/IA PTA \pm stent.
\end{abstract}

Methods and results: The study involved 411 consecutive patients with symptomatic SA/IA stenosis/ occlusion; 393 were followed annually after successful PTA \pm stent for up to 16 (minimum one) years. Primary outcomes were freedom from restenosis and MACCE (cardiovascular death, myocardial infarction, stroke). Angiographic success rate was $99.7 \%$ in stenoses and $76.1 \%$ in occlusions. The incidence of any periprocedural complication was $4.4 \%$ (serious - $1.2 \%$ ). Symptoms of limb ischaemia, vertebrobasilar insufficiency or angina resolved in $79.1 \%$, decreased in $19.6 \%$. Freedom from restenosis was $82.6 \%$ and $77.9 \%$ whereas freedom from MACCE was $86.6 \%$ and $78.3 \%$ at five and 10 years, respectively. MACCE determinants (HR; 95\% CI) were previous myocardial infarction (5.36; 2.9-9.91), ischaemic stroke (2.03; 1.12-3.66), hs-CRP (1.04; 1.02-1.07), concurrent atherosclerosis (1.35; 1.00-1.82). Restenosis determinants were implantation of $\geq 2$ stents $(2.65 ; 1.23-5.72)$, stent diameter $(0.45 ; 0.34-0.59)$, hs-CRP (1.06; 1.02-1.1), WBC $(1.2 ; 1.07-1.35)$, age $(0.97 ; 0.94-0.99)$, concurrent carotid or vertebral disease $(1.85 ; 1.07-3.18)$, IA intervention $(2.28 ; 1.08-4.84)$.

Conclusions: This study established long-term durability of stent-assisted PTA of symptomatic SA/IA disease and identified risk factors for restenosis and long-term MACCE. Patients at increased risk might benefit from targeted, intensified prevention measures.

\footnotetext{
*Corresponding author: Department of Interventional Cardiology, Institute of Cardiology, Jagiellonian University School of Medicine, The John Paul II Hospital, Prądnicka 80, 31-202 Kraków, Poland.E-mail: tadeuszprzewlocki@op.pl
} 


\section{Abbreviations}

$\begin{array}{ll}\text { ACE } & \text { angiotensin-converting enzyme } \\ \text { ACR } & \text { American College of Rheumatology } \\ \text { CABG } & \text { coronary artery bypass grafting } \\ \text { CAD } & \text { coronary artery disease } \\ \text { CVD } & \text { cardiovascular death } \\ \text { DUS } & \text { duplex ultrasound } \\ \text { EPD } & \text { embolic protection device } \\ \text { hs-CRP } & \text { high-sensitivity C-reactive protein } \\ \text { IMA } & \text { internal mammary artery } \\ \text { IS } & \text { ischaemic stroke } \\ \text { IVUS } & \text { intravascular ultrasound } \\ \text { MACCE } & \text { major adverse cardiac and cerebrovascular events } \\ \text { MI } & \text { myocardial infarction } \\ \text { PTA } & \text { percutaneous transluminal angioplasty } \\ \text { RS } & \text { restenosis } \\ \text { SAIIA } & \text { subclavian or innominate artery } \\ \text { SLP } & \text { symptomatic lesion/atherosclerosis progression } \\ \text { UEEI } & \text { upper extremity exertional ischaemia } \\ \text { VBI } & \text { vertebrobasilar insufficiency } \\ \text { WBC } & \text { white blood cell count }\end{array}$

\section{Introduction}

Symptomatic subclavian or innominate artery (SA/IA) stenosis or occlusion is an important cardiovascular pathology $y^{1,2}$. The incidence of SA/IA stenosis is difficult to assess, as the condition is usually asymptomatic ${ }^{1-3}$ : estimates vary from about $0.6-1.9 \%$ of the general population to $8.5 \%$ of patients with substantial coronary artery disease $(\mathrm{CAD})^{1-3}$. A proportion of subjects with substantial SA/IA stenosis suffer from distressing symptoms of end organ ischaemia, including symptoms of vertebrobasilar insufficiency (VBI), upper extremity exertional ischaemia (UEEI) or chest pain in patients after coronary artery bypass graft (CABG) surgery using the internal mammary artery (IMA) $)^{1,2,4,5}$.

Symptomatic SA/IA stenosis or occlusion is an indication for revascularisation, and stent-assisted percutaneous transluminal angioplasty (PTA \pm stent) is generally considered the first-choice strategy ${ }^{6}$. Nevertheless, actual incidence and determinants of restenosis (RS) and of major adverse cardiac and cerebrovascular events (MACCE) following $\mathrm{PTA} \pm$ stent remain unclear due to relatively short-term follow-up or a limited number of participants in previous studies?.

The aim of this study was to assess prospectively long-term outcomes in patients after $\mathrm{PTA} \pm$ stent for symptomatic SA/IA stenosis in terms of the safety, efficacy, and durability of the procedure. We also analysed cardiovascular prognosis in this group, with a focus on predictors of long-term adverse clinical events.

\section{Methods}

Prospective evaluation included all patients with symptomatic SA/ IA stenosis or occlusion referred to our institution between April 2000 and December 2015 for interventional management. The institution is a regional tertiary referral centre with established referral pathways from neurology and vascular clinics that cover a population of around 6 million. The study flow chart is shown in Figure 1. Angiographic, duplex ultrasound (DUS) and clinical data at baseline and follow-up as per study protocol were prospectively collected and entered into an electronic database.

The indication for the procedure was a significant $(>50 \%$ diameter) stenosis or occlusion of the SA/IA with coexisting

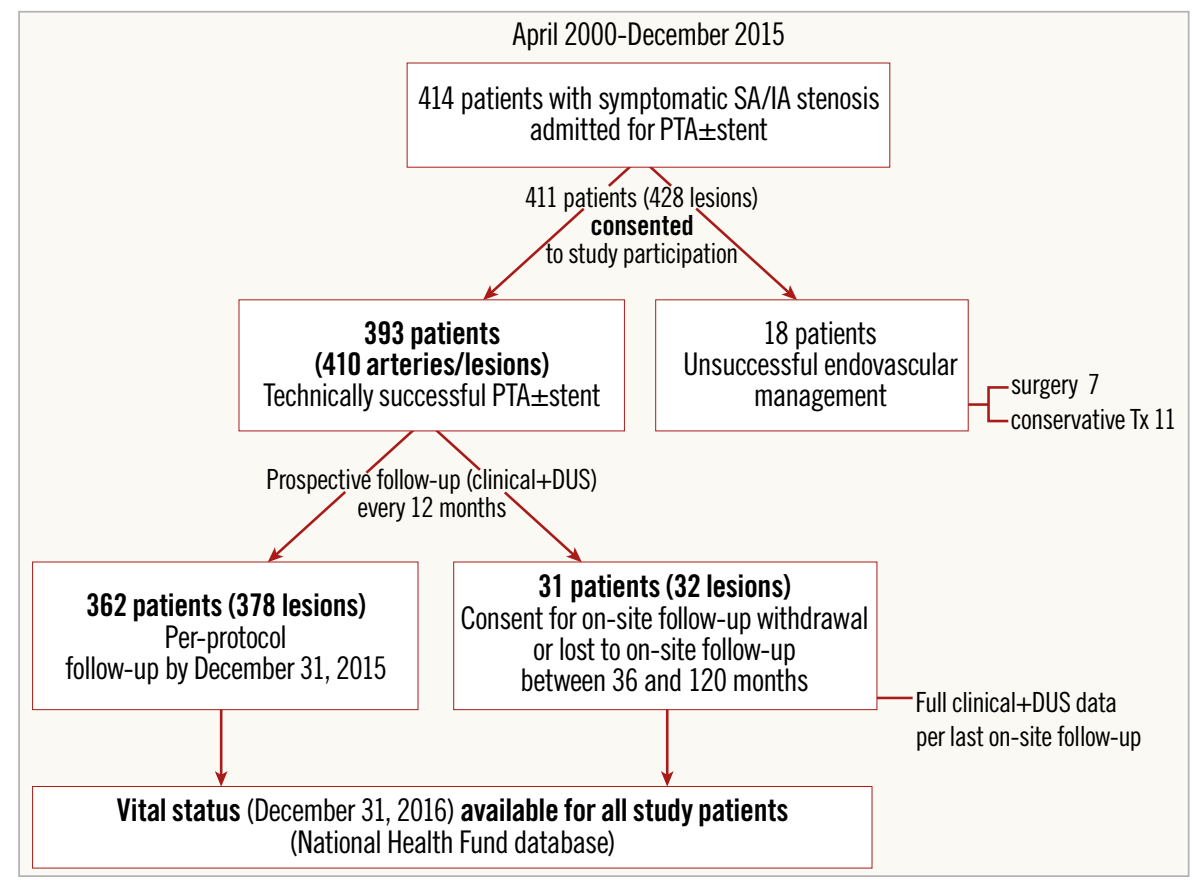

Figure 1. Study protocol. DUS: duplex ultrasonography; SA/IA: subclavian artery/innominate artery 
symptoms of UEEI, of VBI in patients referred for revascularisation by a neurologist, symptoms of cardiac ischaemia in patients after CABG with ipsilateral IMA anastomosed to coronary circulation, planned $\mathrm{CABG}$ with IMA utilisation, or bilateral disease to enable routine blood pressure monitoring.

All patients were assessed for concurrent atherosclerosis in the coronary, carotid, renal and lower extremity arteries on the basis of prior revascularisation or presence of a significant stenosis on DUS, computed tomographic angiography, or invasive angiography. Our study population included symptomatic SA/IA stenosis patients, with a significant proportion of diabetics. Because our experience indicates that 1) CAD status discrimination may be unreliable based on the clinical picture in patients with symptomatic atherosclerosis in other arteries, and 2) routine non-invasive work-up (such as exercise testing) is often inconclusive due to non-coronary exercise-limiting symptoms ${ }^{8,9}$, it was our routine practice to perform, in the absence of a recent definition of the coronary status, coronary angiography simultaneously with the index invasive angiography or angioplasty. In case of revascularisation-requiring CAD coexisting with the SA/IA symptomatic lesion, the decision on the order and mode of revascularisation was made by multispecialty team consensus.

\section{THE ENDOVASCULAR PROCEDURE}

Before the procedure, all patients who were not already on antiplatelet drugs received pre-treatment with a loading dose of $300 \mathrm{mg}$ of acetylsalicylic acid and of thienopyridines. Until the year 2003 ticlopidine was used ( $250 \mathrm{mg}$ b.i.d for $\geq 3$ days) and from 2004 a single loading dose of clopidogrel (300-600 mg) was administered. During the procedure, unfractionated heparin was administered intravenously (70-100 IU/kg) to achieve an activated clotting time $>250$ seconds. After the procedure, a maintenance dose of a thienopyridine was continued for at least three months and of acetylsalicylic acid indefinitely. A statin was prescribed in $98.7 \%$ of patients; other commonly prescribed medications included ACE inhibitor or angiotensin receptor blocker $(89.1 \%)$, beta-blocker $(72 \%)$ and/or calcium channel blocker (32.1\%). Diuretics (36.1\%) were used to support blood pressure or congestive heart failure control.

The majority of procedures were performed via transfemoral (6-8 Fr) access through a guiding catheter or sheath. With total occlusion revascularisation, a double, transradial (5-6 Fr) plus transfemoral approach was employed in most cases. Guidewires and stents were chosen with respect to anatomical conditions and operator discretion. Stenting was the preferred strategy with the exception of several cases where balloon angioplasty alone gave a stent-like result. In prevertebral lesions, there was a general preference for balloon-expandable stents. Self-expanding stents were placed predominantly in peripheral locations and/or long lesions. In the IA and in cases of lesions involving the vertebral artery ostium, embolic protection devices (EPD) were routinely considered, particularly in the absence of a spontaneous vertebral artery flow reversal. For proximal protection, a balloon catheter was inflated in the prevertebral SA segment to reverse the vertebral flow. For distal neuroprotection filters were used. When the index lesion was localised in the vicinity of a vertebral artery exhibiting retrograde flow, the vertebral artery was protected with a guidewire.

The angiographic analysis was performed by a consensus of two cardiovascular technologists, independent of the study team.

The degree of stenosis was expressed as a percentage diameter reduction and was calculated using automated geometric quantitative angiography. Angiographic revascularisation success was defined as residual stenosis of $\leq 30 \%$ and a gradient across the lesion of $\leq 10 \mathrm{mmHg}$. Periprocedural complications were any complications occurring between study enrolment and discharge.

\section{FOLLOW-UP}

The participants were evaluated in the outpatient clinic, first at three to six months and then every 12 months. Primary outcomes were treatment durability (freedom from RS or reintervention) and long-term MACCE (cardiovascular death [CVD], myocardial infarction [MI], stroke [IS]). Other outcomes included periprocedural complications and angiographic and clinical success.

The follow-up evaluation included clinical assessment, bilateral arm pressure measurement, and DUS. The patients were interviewed about specific SA/IA-related symptoms. Index neurological symptoms and their evolution were validated by a consulting neurologist. The diagnosis of stroke was established by a neurologist.

The incidence of CVD, MI, stroke, RS, and symptomatic lesion progression (SLP) requiring revascularisation in any major arterial territory (coronary, carotid/cerebral, renal, iliac, lower extremity) was recorded.

RS was defined as recurrence of at least $50 \%$ reduction of the arterial lumen diameter within the stent or adjacent $5 \mathrm{~mm}$ or in the segment treated with balloon angioplasty. When a new symptomatic stenosis of over $50 \%$ was detected outside of the index segment, in any of the coronary, carotid, subclavian, vertebral, renal, and lower extremity arteries, a diagnosis of SLP was established.

In symptomatic patients suspected of RS or SLP on the basis of clinical and ultrasound examination, computed tomography angiography or invasive angiography was performed. When angina occurred, its underlying mechanism was further investigated. In case of symptomatic RS or SLP, patients underwent repeat revascularisation.

MACCE were CVD, MI or IS. Other adverse events (Figure 2) were considered minor.

CVD was defined as fatal MI, fatal IS or any sudden or unexpected death unless determined to be non-cardiovascular. Primary patency of the target vessel was defined as maintained patency after the index procedure and secondary patency as patency following repeat $\mathrm{PTA} \pm$ stent for $\mathrm{RS}$.

In rare cases of consent withdrawal for on-site follow-up (mostly due to patient transport logistics), the clinical data (other than vital status) and DUS for the last available on-site follow-up were entered into the analysis. The vital status was evaluated for all participants (National Health Fund database, December 2016) (Figure 1). 


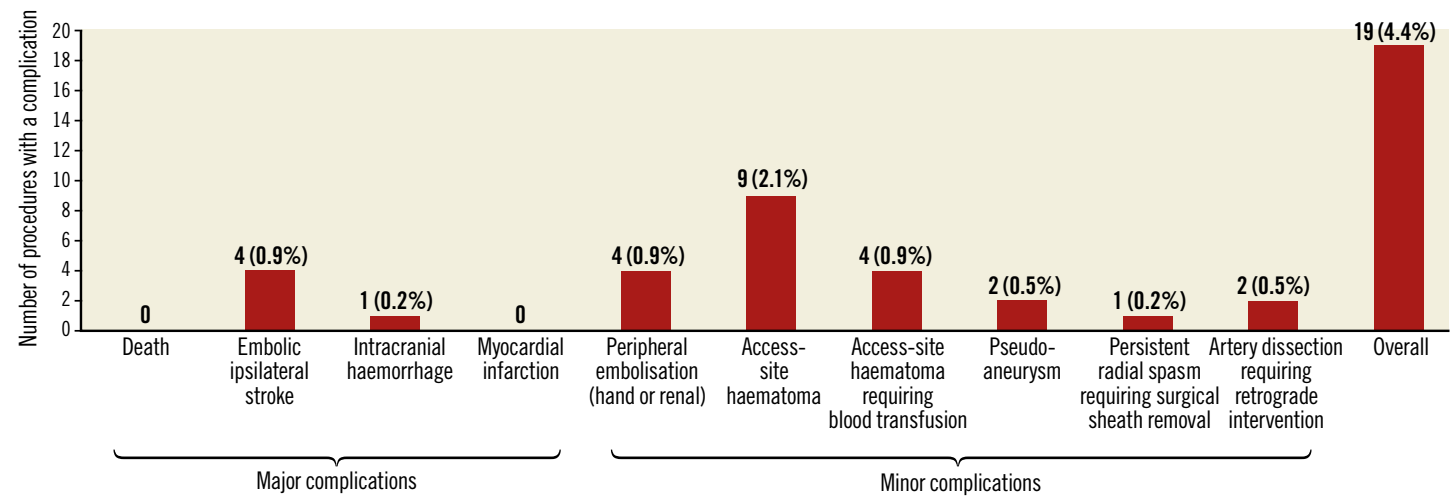

Figure 2. Periprocedural complications during 428 PTA procedures.

The study was performed in accordance with the Declaration of Helsinki. The protocol was reviewed and approved by a local ethics committee. Patients who provided informed consent for participation were enrolled in the study (Figure 1).

\section{STATISTICAL ANALYSIS}

Quantitative data were expressed as the median and quartiles (Q1;Q3). Categorical data were expressed as proportions. Quantitative variables were compared between groups using the Student's t-test, Mann-Whitney U test or analysis of variance, and categorical variables were compared using the $\chi^{2}$ or Fisher's exact test as appropriate.

Times to RS, MACCE, and MACCE plus SLP were analysed using Kaplan-Meier survival curves. As the number of subjects at risk with follow-up over 10 years constituted less than $10 \%$ of the study population, the Kaplan-Meier analysis was performed for up to 10-year follow-up.

To establish long-term predictors of RS, MACCE, and MACCE and SLP, a LASSO (least absolute shrinkage and selection operator) penalised regression model was applied to identify independent associations between RS, MACCE, MACCE plus SLP and potential risk factors, without penalisation of several covariates.
Then adjusted estimates were obtained using a Cox option that stratified risk factors, adjusted for several covariates. The results were considered statistically significant at $p<0.05$. LASSO models were applied with glmnet package in $\mathrm{R}^{10}$. Other statistical analyses were performed with Statistica software v.12.0 (StatSoft Inc., Tulsa, OK, USA).

\section{Results \\ EARLY RESULTS}

Four hundred and eleven consecutive patients (mean age $63.7 \pm 9.6$ years; $53.4 \%$ male) with 428 lesions were enrolled. There were 357 (83.4\%) SA/IA stenoses and 71 (16.6\%) occlusions. Indications for SA/IA revascularisation and clinical characteristics are summarised in Table 1. Atherosclerosis was the predominant $(99.5 \%)$ underlying pathology, and in the majority of cases (77.1\%) the index SA/IA lesion was part of a multilevel atherosclerotic process. In two patients, Takayasu arteritis was diagnosed (consultant rheumatologist) consistent with the ACR criteria. In 18 patients (18 lesions), the percutaneous route was unsuccessful (all failures except one concerned total occlusions; $\mathrm{p}<0.0001$ ); thus, the PTA cohort included 393 patients (410 arteries and lesions) (Figure 1).

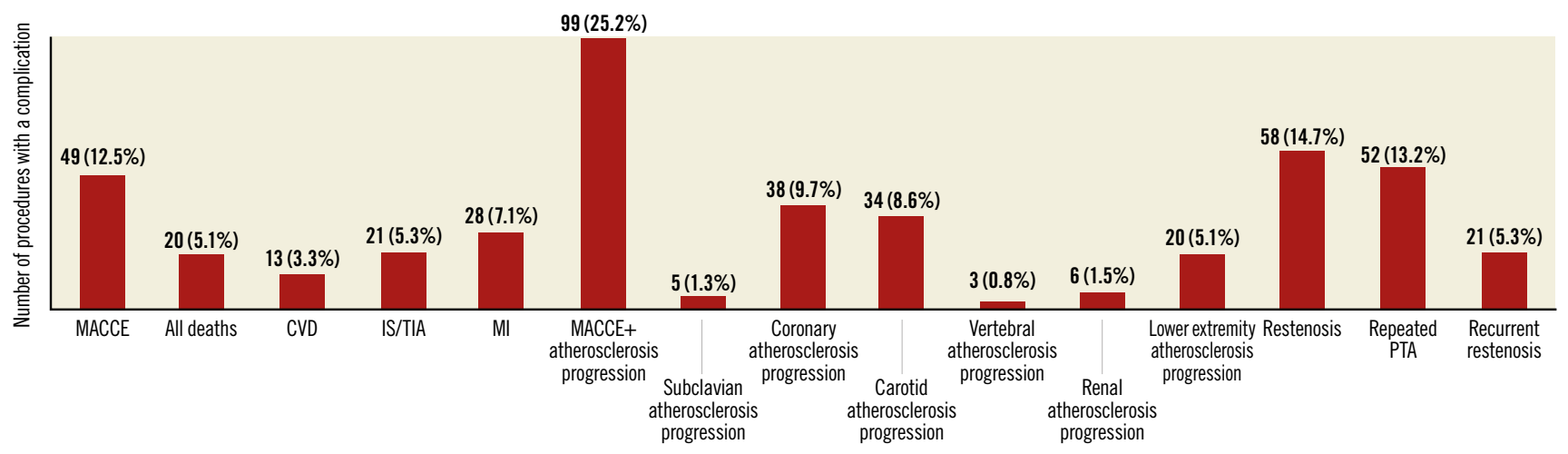

Figure 3. Restenosis rate and incidence of major adverse cardiac and cerebrovascular events in 393 subjects. Some patients experienced more than one event during their follow-up. CVD: cardiovascular death; IS/TIA: ischaemic stroke or transient ischaemic attack; MACCE: major adverse cardiac and cerebrovascular events; MI: myocardial infarction; PTA: percutaneous transluminal angioplasty 
Table 1. Clinical characteristics of the study group and indications for revascularisation $(n=411)$.

\begin{tabular}{|c|c|c|}
\hline \multicolumn{2}{|c|}{ Age (years), mean \pm SD (range) } & $63.7 \pm 9.6(17-91)$ \\
\hline \multicolumn{2}{|c|}{ Male, n (\%) } & $219(53.4)$ \\
\hline \multicolumn{2}{|c|}{ Hypertension, n (\%) } & $351(85.3)$ \\
\hline \multicolumn{2}{|c|}{ Diabetes mellitus, n (\%) } & $116(28.2)$ \\
\hline \multicolumn{2}{|c|}{ Hyperlipidaemia, n (\%) } & $374(90.9)$ \\
\hline \multicolumn{2}{|c|}{ Smoking history, n (\%) } & $278(67.4)$ \\
\hline \multicolumn{2}{|c|}{ Previous MI, n (\%) } & $111(27)$ \\
\hline \multicolumn{2}{|c|}{ Previous IS/TIA, n (\%) } & $99(24.3)$ \\
\hline \multicolumn{2}{|c|}{ Coronary artery disease, $\mathrm{n}(\%)$} & $232(56.1)$ \\
\hline \multicolumn{2}{|c|}{ Renal artery stenosis, n (\%) } & $30(7.4)$ \\
\hline \multicolumn{2}{|c|}{ Peripheral artery disease, $\mathrm{n}(\%)$} & $123(29.4)$ \\
\hline \multicolumn{2}{|c|}{ Carotid or vertebral artery disease, $\mathrm{n}(\%)$} & $151(37)$ \\
\hline \multicolumn{2}{|c|}{ Previous revascularisation, n (\%) } & 131 (31.9) \\
\hline \multirow{3}{*}{$\begin{array}{l}\text { SA/IA } \\
\text { disease } \\
\text { aetiology }\end{array}$} & Atherosclerosis, n (\%) & $403(98.1)$ \\
\hline & Takayasu arteritis, n (\%) & $7(1.7)$ \\
\hline & Connective tissue disorder, n (\%) & $1(0.2)$ \\
\hline \multicolumn{3}{|c|}{ Indications for procedure } \\
\hline \multicolumn{2}{|c|}{ VBI, n (\%) } & $142(34.8)$ \\
\hline \multicolumn{2}{|c|}{ UEEI, n (\%) } & $36(8.8)$ \\
\hline \multicolumn{2}{|c|}{ VBI and UEEI, n (\%) } & $197(47.6)$ \\
\hline \multicolumn{2}{|c|}{$\begin{array}{l}\text { Coronary-subclavian steal or planned LIMA to } \\
\text { LAD graft, } \mathrm{n}(\%)\end{array}$} & $31(7.6)$ \\
\hline \multicolumn{2}{|c|}{$\begin{array}{l}\text { Enabling blood pressure monitoring in } \\
\text { asymptomatic patients with bilateral SA/IA, n (\%) }\end{array}$} & $5(1.2)$ \\
\hline \multicolumn{3}{|c|}{$\begin{array}{l}\text { IS/TIA: ischaemic stroke/transient ischaemic attack; LIMA to LAD: left } \\
\text { internal mammary artery to left anterior descending coronary branch; } \\
\text { MI: myocardial infarction; SA/IA: subclavian/innominate artery; } \\
\text { UEEI: upper extremity exertional ischaemia; VBI: vertebrobasilar } \\
\text { insufficiency }\end{array}$} \\
\hline
\end{tabular}

The PTA efficacy was significantly higher in stenoses than in occlusions $(99.7 \%$ vs. $76.1 \% ; \mathrm{p}<0.0001)$, though the success rate in occlusion management increased with time and availability of novel techniques (from $69.8 \%$ [ 23 of 33 procedures] in 2001-2009 to $81.6 \%$ [31 of 38 procedures] in 2010-2016). Detailed procedural data are given in Table 2. Any periprocedural complications occurred in 19 procedures (4.4\%) (Figure 2).

At three to six months, all the UEEI and coronary-subclavian steal patients were free from symptoms. Of the 339 patients with VBI on enrolment, total symptom resolution occurred in 249 (73.5\%). The remaining 88 (26\%) patients declared a significant reduction in VBI symptom intensity and/or occurrence. There was no improvement in five $(0.5 \%)$ patients.

\section{LATE RESULTS}

The median follow-up time was 60 months (up to 192 months, minimum 12 months). During this period, MACCE occurred in 49 $(12.5 \%)$ patients. MACCE+SLP in either subclavian, carotid, vertebral, coronary, renal or lower extremity arteries occurred in 99 (25.2\%) patients. MACCE and other events are listed in Figure 3.
Table 2. Lesion characteristics and overview of procedures.

\begin{tabular}{|c|c|c|}
\hline \multicolumn{2}{|c|}{ Number of patients/number of lesions treated with PTA \pm stent } & $411 / 428$ \\
\hline \multicolumn{2}{|c|}{ Innominate artery disease (per total procedures), $n(\%)$} & $30(7.0)$ \\
\hline \multicolumn{2}{|c|}{ Right subclavian artery disease (per total procedures), $\mathrm{n}(\%)$} & $84(19.6)$ \\
\hline \multicolumn{2}{|c|}{ Left subclavian artery disease (per total procedures), n (\%) } & $314(73.4)$ \\
\hline \multicolumn{2}{|l|}{ Bilateral PTA, n (\%) } & $17(4.2)$ \\
\hline \multicolumn{2}{|l|}{ Occlusion, $\mathrm{n}(\%)$} & $71(16.6)$ \\
\hline \multicolumn{2}{|c|}{ Lesions localised distal to the vertebral artery, $\mathrm{n}(\%)$} & $10(2.3 \%)$ \\
\hline \multicolumn{2}{|c|}{ Ultrasound evidence of subclavian steal syndrome, $n(\%)$} & $293(71.1)$ \\
\hline \multicolumn{3}{|c|}{ Percent stenosis of SA/IA, \% } \\
\hline \multicolumn{2}{|c|}{ before PTA \pm stent, median $(Q 1 ; Q 3)$} & $80(67 ; 90)$ \\
\hline \multicolumn{2}{|c|}{ after PTA \pm stent, median $(Q 1 ; Q 3)$} & $12(7 ; 20)$ \\
\hline \multicolumn{3}{|c|}{ Peak systolic velocity assessed by DUS, $\mathrm{m} / \mathrm{s}$} \\
\hline \multicolumn{2}{|c|}{ before PTA \pm stent, median $(Q 1 ; Q 3)$} & $5(4.0 ; 5.73)$ \\
\hline \multicolumn{2}{|c|}{ after PTA \pm stent, median $(Q 1 ; Q 3)$} & $2(1.3 ; 2.2)$ \\
\hline \multicolumn{3}{|c|}{ Inter-arm systolic blood pressure difference, mmHg } \\
\hline \multicolumn{2}{|c|}{ before PTA \pm stent, median $(\mathrm{Q} 1 ; \mathrm{Q} 3)$} & $30(20 ; 50)$ \\
\hline \multicolumn{2}{|c|}{ after PTA \pm stent, median $(Q 1 ; Q 3)$} & $0(0 ; 10)$ \\
\hline \multicolumn{3}{|l|}{ Vascular access } \\
\hline \multirow{3}{*}{$\begin{array}{l}\text { In stenoses } \\
(\mathrm{N}=357)\end{array}$} & transfemoral access, $\mathrm{n}(\%)$ & $343(96.1)$ \\
\hline & radial/brachial access, n (\%) & $9(2.5)$ \\
\hline & double-site access, n (\%) & $14(3.9)$ \\
\hline \multirow{3}{*}{$\begin{array}{l}\text { In total occlusions } \\
(\mathrm{N}=71)\end{array}$} & transfemoral access, $n(\%)$ & $32(45.1)$ \\
\hline & radial/brachial access, $n(\%)$ & $3(4.2)$ \\
\hline & double-site access, $n(\%)$ & $36(50.7)$ \\
\hline \multicolumn{2}{|c|}{ Successful PTA \pm stent (patients; procedure), n (\%) } & $\begin{array}{l}393 \text { (95.6); } \\
411 \text { (95.8) }\end{array}$ \\
\hline \multicolumn{2}{|l|}{ in stenoses, $\mathrm{n}(\%)$} & $356 / 357(99.7)$ \\
\hline \multicolumn{2}{|l|}{ in occlusions, $\mathrm{n}(\%)$} & $54 / 71(76.1)$ \\
\hline \multicolumn{2}{|c|}{ Balloon angioplasty (successful PTA \pm stent), $n(\%)$} & $17 / 410(4.1)$ \\
\hline \multicolumn{2}{|c|}{ Stent implantation (successful PTA \pm stent), n (\%) } & $393 / 410(95.8)$ \\
\hline \multicolumn{2}{|c|}{ Number of implanted stents } & 427 \\
\hline 1 stent per lesion, $n$ & (\%) & $365 / 393(93.9)$ \\
\hline$\geq 2$ stents per lesion & $n(\%)$ & $28 / 393(6.9)$ \\
\hline Stent length (mm), medi & an $(Q 1 ; Q 3)$ & $\begin{array}{c}24(18 ; 30), \\
\text { (range 12-106) }\end{array}$ \\
\hline Stent diameter $(\mathrm{mm}), \mathrm{m \epsilon}$ & $\operatorname{dian}(Q 1 ; Q 3)$ & $\begin{array}{c}8(7 ; 8), \\
\text { (range 4-10) }\end{array}$ \\
\hline Balloon-expandable sten & t implantation, $n(\%)$ & $328 / 393(83.5)$ \\
\hline Self-expanding stent imp & lantation, $\mathrm{n}(\%)$ & 94/393 (23.9) \\
\hline Direct stenting, $n(\%)$ & & $216 / 393(55)$ \\
\hline Embolic protection devic & (in successful PTA \pm stent), $n$ (\%) including & $18 / 410(4.4)$ \\
\hline Proximal & & $5(1.2)$ \\
\hline Distal & & $13(3.2)$ \\
\hline Concurrent vertebral arte & ry angioplasty, n (\%) & $32(7.5)$ \\
\hline Stenting & & 31 \\
\hline Balloon angioplasty & & 1 \\
\hline Guidewire protection of $t$ & ne vertebral artery (without PTA \pm stent), $\mathrm{n}(\%)$ & $17 / 410(4.2)$ \\
\hline
\end{tabular}


MACCE-free survival at one, five, and 10 years was $96.3 \%$, $86.6 \%$, and $78.3 \%$, and MACCE+SLP-free survival was $92.0 \%$, $72.1 \%$, and $56 \%$, respectively (Figure $4 \mathrm{~A}$ ). Independent predictors of MACCE were previous MI or IS, concurrent atherosclerosis in other vascular beds (carotid, coronary, renal, lower extremity) and an increased hs-CRP level. Independent predictors of the combined endpoint of MACCE and SLP additionally included diabetes mellitus (Figure 5).

RS occurred in $58(14.7 \%)$ patients. Time to RS ranged from four months up to 10 years. In 54 (93.1\%) cases, RS was related to symptom re-occurrence. Among the symptomatic RS patients, 52 underwent repeat $\mathrm{PTA} \pm$ stent whereas carotid-subclavian bypass graft surgery was performed in two. The remaining four asymptomatic patients were managed conservatively. Recurrent RS developed in $21(40.4 \%)$ of the 52 patients who underwent re-PTA \pm stent; 18 of these were again treated with PTA, one underwent a carotid-subclavian bypass graft surgery, and the remaining two asymptomatic patients were managed conservatively. In three $(0.8 \%)$ patients the endovascular treatment was repeated four times.

RS was significantly more prevalent in the IA as compared to the SA $(30 \%$ [9 of 30] vs. 9.5\% [8 of 84 , right SA] or $13.1 \%$ [41 of 314, left SA]; $\mathrm{p}=0.012$ ). Independent predictors of RS were increased level of hs-CRP or WBC, younger age, small stent diameter, placement of $\geq 2$ stents per lesion, concurrent internal carotid or vertebral stenosis, and intervention in the IA rather than SA (Figure 5).

Concomitant vertebral angioplasty during SA/IA stenting was not associated with MACCE (HR 1.628, 95\% CI: 0.691-3.836; $\mathrm{p}=0.265$ ) or RS risk (HR 1.046, 95\% CI: 0.418-2.619; $\mathrm{p}=0.924$ ).
At the one, five and 10-year follow-up, the primary patency rate was $92.7 \%, 82.6 \%$ and $77.9 \%$, respectively (Figure 4B). The respective secondary patency rate was $99 \%, 96.3 \%$ and $95.1 \%$ (Figure 4B). SA/IA disease progression was noted in five $(1.3 \%)$ patients; all of these were symptomatic and underwent successful $\mathrm{PTA} \pm$ stent.

\section{Discussion}

This study not only addressed essential aspects of safety and durability of the endovascular management of symptomatic SA/IA but also provided new insights into determinants of long-term outcome in this patient population.

Endoluminal revascularisation of SA/IA is safe when performed in a high-volume centre. In this study, the periprocedural complication rate was relatively low $(4.4 \%$, inclusive of $1.2 \%$ serious complications) and was in line with other reports that indicated a $4.5-9.2 \%$ rate of complications ${ }^{7,11-16}$. EPD may reduce complications during endoluminal procedures; however, their role in PTA of SA/IA is still a matter of debate ${ }^{17}$. Our strategy involved EPD consideration in case of thrombus-containing or soft large plaques, particularly when the vertebral artery ostium was involved and in the absence of spontaneous vertebral flow reversal. Interestingly, none of the embolic complications in our study occurred in EPDassisted procedures. This does not indicate that EPD use should be routine in SA/IA procedures because inappropriate EPD usage can be causally associated with complications. We believe, however, that EPD should be considered in high-risk lesions.

This study shows that SA/IA endoluminal repair is effective as it leads to total symptom resolution in the vast majority of patients, whereas nearly all others experience clinically
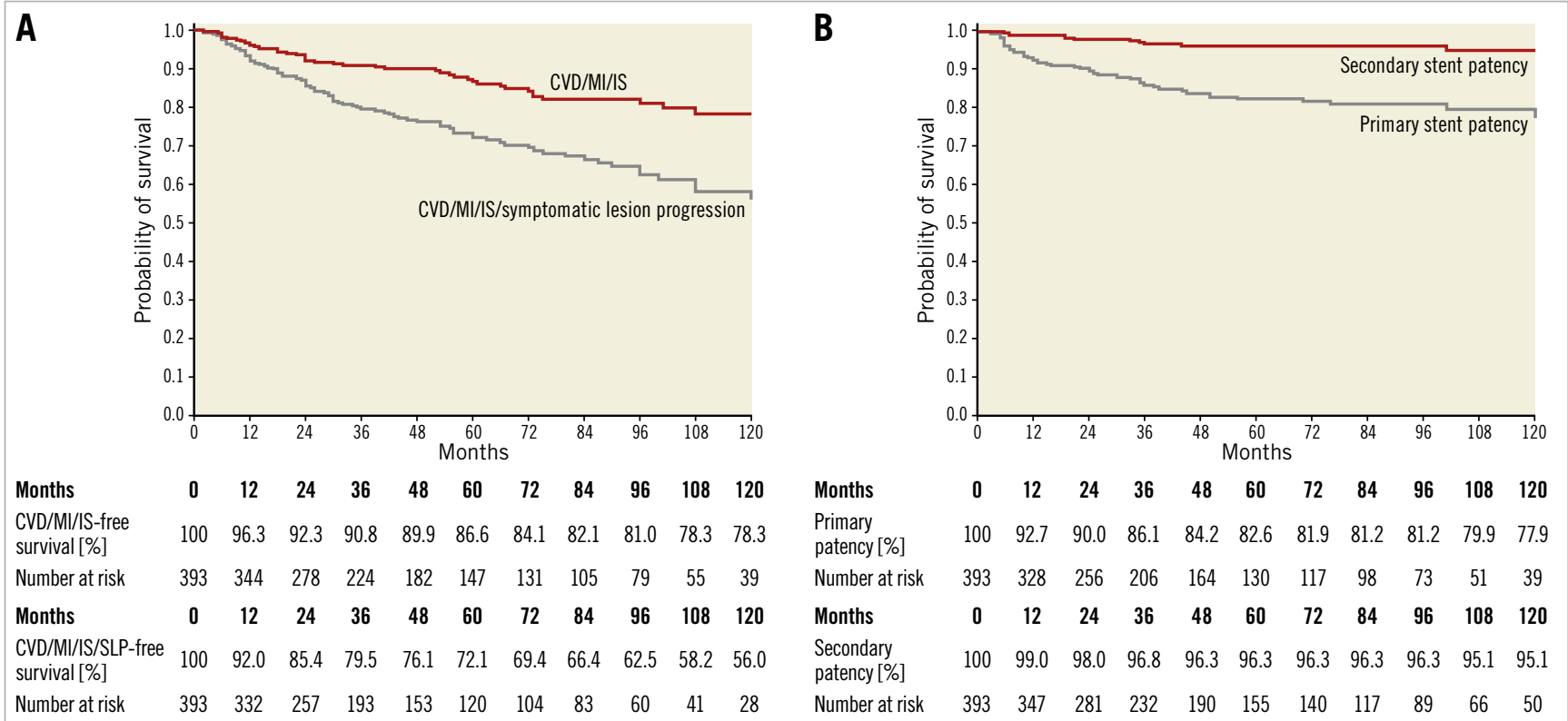

$\begin{array}{lccccccccccc}\text { Months } & \mathbf{0} & \mathbf{1 2} & \mathbf{2 4} & \mathbf{3 6} & \mathbf{4 8} & \mathbf{6 0} & \mathbf{7 2} & \mathbf{8 4} & \mathbf{9 6} & \mathbf{1 0 8} & \mathbf{1 2 0} \\ \text { CVD/MI/IS-free } & 100 & 96.3 & 92.3 & 90.8 & 89.9 & 86.6 & 84.1 & 82.1 & 81.0 & 78.3 & 78.3 \\ \text { survival [\%] } & 192 & & & & & & & & & & \\ \text { Number at risk } & 393 & 344 & 278 & 224 & 182 & 147 & 131 & 105 & 79 & 55 & 39 \\ \text { Months } & \mathbf{0} & \mathbf{1 2} & \mathbf{2 4} & \mathbf{3 6} & \mathbf{4 8} & \mathbf{6 0} & \mathbf{7 2} & \mathbf{8 4} & \mathbf{9 6} & \mathbf{1 0 8} & \mathbf{1 2 0} \\ \begin{array}{l}\text { CVD/MI/IS/SLP-free } \\ \text { survival [\%] }\end{array} & 100 & 92.0 & 85.4 & 79.5 & 76.1 & 72.1 & 69.4 & 66.4 & 62.5 & 58.2 & 56.0 \\ \text { Number at risk } & 393 & 332 & 257 & 193 & 153 & 120 & 104 & 83 & 60 & 41 & 28\end{array}$

Figure 4. Kaplan-Meier curves. A) Long-term survival free from MACCE and MACCE with symptomatic lesion progression. B) Primary and secondary vessel patency. SLP: symptomatic lesion progression 


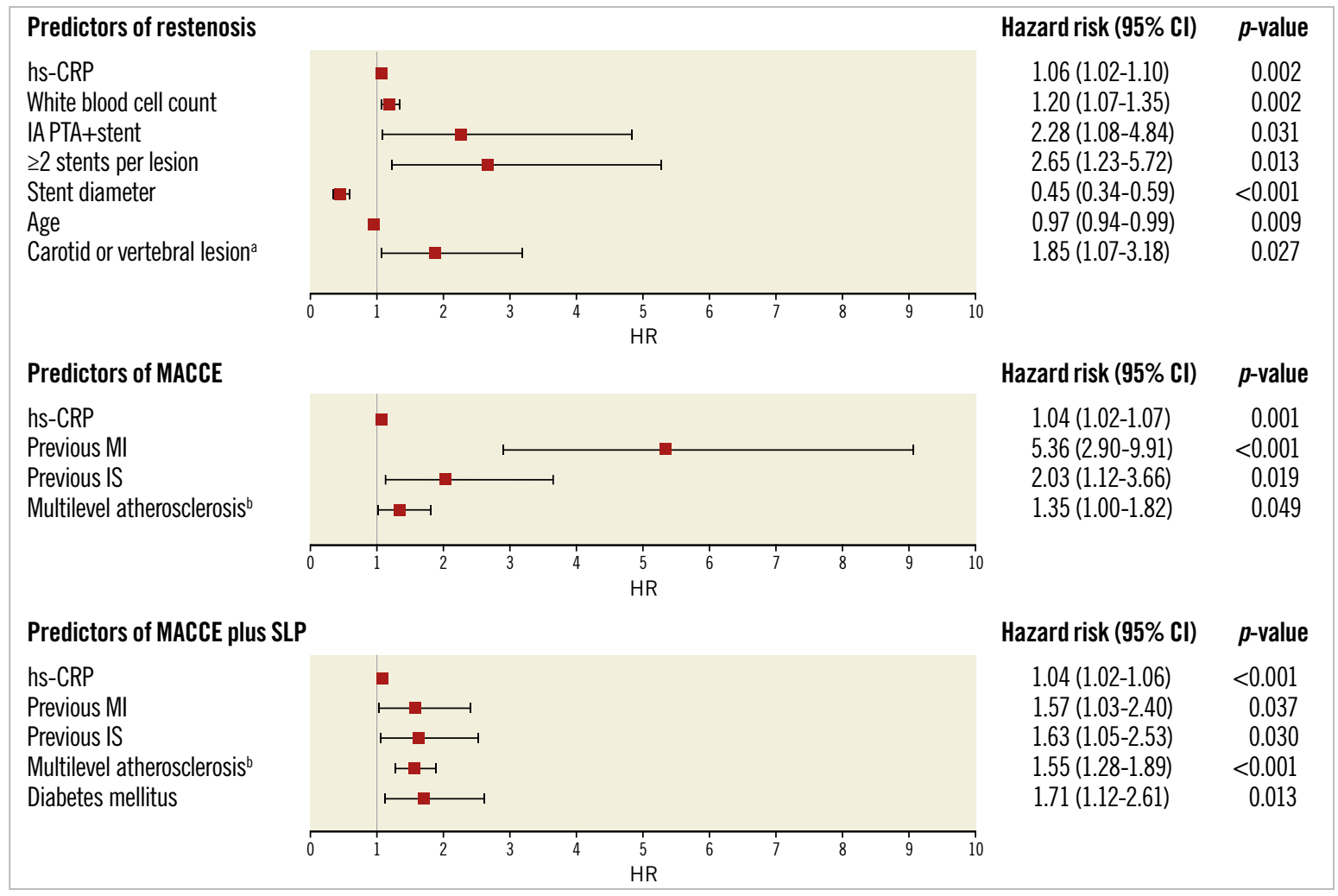

Figure 5. Independent predictors of restenosis, MACCE and MACCE or symptomatic lesion progression. ${ }^{a}$ concurrent stenosis $\geq 50 \%$ or occlusion. ${ }^{b}$ concurrent stenosis $\geq 50 \%$ or occlusion in carotid, coronary, renal or lower extremity arteries. IA: innominate artery; IS: ischaemic stroke; MACCE: major adverse cardiac and cerebrovascular events; MI: myocardial infarction; SLP: symptomatic lesion progression requiring revascularisation in any arterial territory

meaningful symptom reduction. Symptoms of coronary ischaemia or UEEI resolved in all cases. VBI symptoms persisted in some. It seems likely that the lower resolution rate of VBI symptoms may result from their poorer specificity, at least in some patients ${ }^{18}$.

There have been suggestions that routine stenting for SA/IA stenosis is superior to plain PTA with respect to long-term results ${ }^{12,13}$. Our study, similar to a recent meta-analysis ${ }^{19}$, suggested no differences in rates of RS and symptom resolution between stentassisted procedures and balloon angioplasty (with a "no-stent" strategy limited to stent-like angiographic results of balloon angioplasty). Nevertheless, stent-like results of balloon-only angioplasty were rare.

The restenosis rate is relatively low and usually associated with symptom recurrence. Although restenosis remains the major limitation of the long-term success of SA/IA endoluminal treatment, long-term patency may by improved with a repeat procedure leading to a high secondary patency ${ }^{11,13,14,16,17}$.

The principal risk factors of RS included younger age, small stent diameter, and several new predictors such as placement of $\geq 2$ stents per lesion, increased inflammatory status, concomitant internal carotid or vertebral stenosis, and intervention in the IA rather than SA. The latter finding is consistent with limited prior evidence for a higher prevalence of RS in the IA than in the SA
$(31.4 \% \text { vs. } 7.5 \%, p=0.06)^{20}$. This phenomenon might result from placement of suboptimal diameter stents due to underestimation of the IA size, perceived risk of right cerebral embolic complications with stent "optimisation", and limited availability of stents sufficiently large in diameter. Two recent reports suggested routine consideration of IVUS use in IA revascularisation ${ }^{11,21}$; this, however, can only in part address the issue.

Importantly, our present work shows that RS risk extends late after the index procedure. Rather than "simple" RS, this phenomenon may be attributable to neoatherosclerosis with in-stent lesion formation, similar to observations in the coronary arteries ${ }^{22}$. Late RS occurrence mandates long-term follow-up of patients, which should include clinical assessment, bilateral arm-pressure measurement, and DUS ${ }^{11,15,18,23}$.

Symptom recurrence is generally attributed to $\mathrm{RS}^{16}$. In this context, the present findings are consistent with our pilot analysis ${ }^{18}$ and indicate that routine clinical follow-up is advisable.

Significant CAD was present in over half of our cohort whereas carotid or vertebral artery disease was present in over a third. Our angiographic verification of $\mathrm{CAD}$ in patients with symptomatic SA/IA disease provides a unique confirmation of previous, noninvasive indications of the clinical value of inter-arm blood pressure difference ${ }^{24,25}$. 
The present study expands our earlier findings ${ }^{26}$ by demonstrating that increased hs-CRP, previous MI or IS and multilevel atherosclerosis were significant predictors of MACCE. Therefore, we believe that it may be vital to assess routinely, during the diagnostic work-up, other major vascular beds streaming a particularly strict risk factor control and pharmacologic prevention to increased-risk patients.

\section{Limitations}

The present work does not represent a randomised study which might be considered an apparent limitation. However, the current state of overall evidence for symptomatic SA/IA endovascular repair benefit precludes effective randomisation to endovascular revascularisation vs. medical therapy or surgery. Due to limited funding, we were unable to perform randomisation to routine EPD-assisted vs. "unprotected" SA/IA endovascular management. The registry included procedures performed over a long period of time, during which available equipment, percutaneous techniques, and ancillary pharmacotherapy changed, which might have influenced the analysis. Nevertheless, our results represent contemporary real-world practice in an all-comer symptomatic population in a high-volume tertiary referral centre.

\section{Conclusions}

Routine endoluminal stent-assisted management of symptomatic SA/IA disease is safe and is highly effective in symptom resolution. With contemporary equipment and procedure optimisation, both the lesion-level and clinical effects are durable. Symptomatic $\mathrm{RS}$ is not frequent; it is reliably diagnosed combining clinical evaluation and DUS. In the vast majority of patients, RS can be effectively managed with a repeat endovascular procedure. As RS may occur many years after the intervention, prolonged followup is mandated. Major risk factors for long-term MACCE following endovascular treatment of symptomatic SA/IA atherosclerosis are symptomatic disease in other vascular territories (cerebral and coronary in particular) and increased inflammatory markers. Patients at increased risk of MACCE might benefit from targeted, intensified prevention measures.

\section{Impact on daily practice}

Patients with symptomatic SA/IA disease should be revascularised optimally with endovascular techniques as the initial strategy. The procedure is relatively safe and highly effective, particularly in stenoses. Implantation of $\geq 2$ stents and stents which are too small should be avoided. RS may limit the long-term benefit; however, it can be effectively managed with a repeat procedure. Since the risk of RS extends to several years, long-term follow-up is advisable. Cardiovascular events in patients after subclavian stent-assisted PTA are related to coexisting coronary and cerebrovascular atherosclerosis and inflammatory status. For this reason, assessment of other major arteries and intensified prevention measures are advisable.

\section{Funding}

This study was supported by a research grant from the Jagiellonian University (K/ZDS/005643).

\section{Conflict of interest statement}

The authors have no conflicts of interest to declare.

\section{References}

1. Shadman R, Criqui $M H$, Bundens WP, Fronek A, Denenberg JO, Gamst AC, McDermott MM. Subclavian artery stenosis: prevalence, risk factors, and association with cardiovascular diseases. J Am Coll Cardiol. 2004;44:618-23.

2. Labropoulos N, Nandivada P, Bekelis K. Prevalence and impact of the subclavian steal syndrome. Ann Surg. 2010;252: 166-70.

3. Przewłocki T, Kabłak-Ziembicka A, Kozanecki A, Rzeźnik D, Pieniazek P, Musiałek P, Piskorz A, Sokołowski A, Rosławiecka A, Tracz W. Polyvascular extracoronary atherosclerotic disease in patients with coronary artery disease. Kardiol Pol. 2009;67: 978-84.

4. Tomoi Y, Soga Y, Fujihara M, Iida O, Shintani Y, Zen K, Ando K. Outcomes of Endovascular Therapy for Upper Extremity Peripheral Artery Disease With Critical Hand Ischemia. J Endovasc Ther. 2016;23:717-22.

5. Sintek M, Coverstone E, Singh J. Coronary subclavian steal syndrome. Curr Opin Cardiol. 2014;29:506-13.

6. European Stroke Organisation, Tendera M, Aboyans V, Bartelink ML, Baumgartner I, Clément D, Collet JP, Cremonesi A, De Carlo M, Erbel R, Fowkes FG, Heras M, Kownator S, Minar E, Ostergren J, Poldermans D, Riambau V, Roffi M, Röther J, Sievert H, van Sambeek M, Zeller T; ESC Committee for Practice Guidelines. ESC Guidelines on the diagnosis and treatment of peripheral artery diseases: Document covering atherosclerotic disease of extracranial carotid and vertebral, mesenteric, renal, upper and lower extremity arteries: the Task Force on the Diagnosis and Treatment of Peripheral Artery Diseases of the European Society of Cardiology (ESC). Eur Heart J. 2011;32:2851-906.

7. Brountzos EN, Petersen B, Binkert C, Panagiotou I, Kaufman JA. Primary stenting of subclavian and innominate artery occlusive disease: a single center's experience. Cardiovasc Intervent Radiol. 2004;27:616-23.

8. Musialek P, Mazurek A, Trystula M, Borratynska A, LesniakSobelga A, Urbanczyk M, Banys RP, Brzychczy A, Zajdel W, Partyka L, Zmudka K, Podolec P. Novel PARADIGM in carotid revascularisation: Prospective evaluation of All-comer peRcutaneous cArotiD revascularisation in symptomatic and Increased-risk asymptomatic carotid artery stenosis using CGuard ${ }^{\mathrm{TM}}$ MicroNetcovered embolic prevention stent system. EuroIntervention. 2016;12:e658-70.

9. Pieniążek P, Tekieli L, Musiałek P, Kabłak Ziembicka A, Przewłocki T, Motyl R, Dzierwa K, Paluszek P, Hlawaty M, Żmudka K, Podolec P. Carotid artery stenting according to the tailored-CAS algorithm is associated with a low complication rate at 
30 days: data from the TARGET-CAS study. Kardiol Pol. 2012; 70:378-86.

10. Friedman J, Hastie T, Tibshirani R. Regularization Paths for Generalized Linear Models via Coordinate Descent. J Stat Softw. 2010;33:1-22.

11. Soga Y, Tomoi Y, Fujihara M, Okazaki S, Yamauchi Y, Shintani Y, Suzuki K; SCALLOP Investigators. Perioperative and Long-term Outcomes of Endovascular Treatment for Subclavian Artery Disease From a Large Multicenter Registry. J Endovasc Ther. 2015;22:626-33.

12. Byrne C, Tawfick W, Hynes N, Sultan S. Ten-year experience in subclavian revascularisation. A parallel comparative observational study. Vascular. 2016;24:378-82.

13. Patel SN, White CJ, Collins TJ, Daniel GA, Jenkins JS, Reilly JP, Morris RF, Ramee SR. Catheter-based treatment of the subclavian and innominate arteries. Catheter Cardiovasc Interv. 2008;71:963-8.

14. Van de Weijer MA, Vonken EJ, de Vries JP, Moll FL, Vos JA, de Borst GJ. Technical and Clinical Success and Long-Term Durability of Endovascular Treatment for Atherosclerotic Aortic Arch Branch Origin Obstruction: Evaluation of 144 Procedures. Eur J Vasc Endovasc Surg. 2015;50:13-20.

15. Mousa AY, AbuRahma AF, Bozzay J, Broce M, Barsoum E, Bates M. Anatomic and clinical predictors of reintervention after subclavian artery stenting. J Vasc Surg. 2015;62:106-14.

16. Bradaric C, Kuhs K, Groha P, Dommasch M, Langwieser N, Haller B, Ott I, Fusaro M, Theiss W, von Beckerath N, Kastrati A, Laugwitz KL, Ibrahim T. Endovascular therapy for steno-occlusive subclavian and innominate artery disease. Circ J. 2015;79:537-43.

17. Liu Y, Zhang J, Gu Y, Guo L, Li J. Clinical Effectiveness of Endovascular Therapy for Total Occlusion of the Subclavian Arteries: A Study of 67 Patients. Ann Vasc Surg. 2016;35:189-96.

18. Wrotniak L, Kablak-Ziembicka A, Rosławiecka A, Musiałek P, Bogacki P, Trystuła M, Żmudka K, Przewłocki T.
Resolution of ischemic symptoms after percutaneous angioplasty for a symptomatic subclavian artery stenosis. J Vasc Surg. 2016;64:684-91.

19. Ahmed A, Mohammed K, Chehab M, Brinjikji W, Murad M, Cloft H, Bjarnason H. Comparing Percutaneous Transluminal Angioplasty and Stent Placement for Treatment of Subclavian Arterial Occlusive Disease: A Systematic Review and MetaAnalysis. Cardiovasc Intervent Radiol. 2016;39:652-67.

20. Karpenko A, Starodubtsev V, Ignatenko P, Gostev A. Endovascular Treatment of the Subclavian Artery Steno-Occlusive Disease. J Stroke Cerebrovasc Dis. 2017;26:87-93.

21. Wada T, Takayama K, Taoka T, Nakagawa H, Myouchin K, Miyasaka T, Akashi T, Sakamoto M, Kichikawa K. Long-term treatment outcomes after intravascular ultrasound evaluation and stent placement for atherosclerotic subclavian artery obstructive lesions. Neuroradiol J. 2014;27:213-21.

22. Roleder T, Jąkała J, Kałuża G, Partyka L, Proniewska K, Pociask E, Zasada W, Wojakowski W, Gąsior Z, Dudek D. The basics of intravascular optical coherence tomography. Adv Interv Cardiol. 2015;11:74-83.

23. Ochoa VM, Yeghiazarians Y. Subclavian artery stenosis: a review for the vascular medicine practitioner. Vasc Med. 2010;16:29-34.

24. Clark CE, Campbell JL, Evans PH, Millward A. Prevalence and clinical implications of the inter-arm blood pressure difference: A systematic review. J Hum Hypertens. 2006;20:923-31.

25. Kim SA, Kim JY, Park JB. Significant interarm blood pressure difference predicts cardiovascular risk in hypertensive patients: CoCoNet study. Medicine (Baltimore). 2016;95:e3888.

26. Kablak-Ziembicka A, Przewlocki T, Stępień E, Pieniążek P, Rzeźnik D, Sliwiak D, Komar M, Tracz W, Podolec P. Relationship between carotid intima-media thickness, cytokines, atherosclerosis extent and a two-year cardiovascular risk in patients with arteriosclerosis. Kardiol Pol. 2011;69:1024-31. 